\title{
UCRL-JRNL-224255
}

LA W REN CE LIVERM ORE NATIONAL LABORATORY

Investigation of network heterogeneities in filled, trimodal, highly functional PDMS networks by $1 \mathrm{H}$ Multiple Quantum NMR

Erica Gjersing, Sarah Chinn, Robert S. Maxwell, Julie Herberg, Eric Eastwood, Dan Bowen, Tom Stephens

September 7, 2006

Macromolecules 
This document was prepared as an account of work sponsored by an agency of the United States Government. Neither the United States Government nor the University of California nor any of their employees, makes any warranty, express or implied, or assumes any legal liability or responsibility for the accuracy, completeness, or usefulness of any information, apparatus, product, or process disclosed, or represents that its use would not infringe privately owned rights. Reference herein to any specific commercial product, process, or service by trade name, trademark, manufacturer, or otherwise, does not necessarily constitute or imply its endorsement, recommendation, or favoring by the United States Government or the University of California. The views and opinions of authors expressed herein do not necessarily state or reflect those of the United States Government or the University of California, and shall not be used for advertising or product endorsement purposes. 


\section{Investigation of network heterogeneities in filled, trimodal, highly functional PDMS networks by ${ }^{1} \mathrm{H}$} Multiple Quantum NMR

Erica Gjersing ${ }^{4}$, Sarah Chinn ${ }^{1}$, Robert S. Maxwell ${ }^{*}$, Julie Herberg ${ }^{1}$, Eric Eastwood ${ }^{2}$, Dan Bowen $^{2}$, Tom Stephens ${ }^{3}$,

1) Lawrence Livermore National Laboratory, 7000 East Ave, Livermore, CA 94551; 2) Honeywell Federal Manufacturing and Technologies Plant, Kansas City, MO; 3) Los Alamos National Laboratory, Los Alamos, NM; 4) Department of Chemical Engineering and Materials Science, University of California, Davis, Davis, CA

\section{RECEIVED DATE}

TITLE RUNNING HEAD.

*CORRESPONDING AUTHOR FOOTNOTE. Ph: (925) 423-4991; fax: (925) 423-3720; email: Maxwel17@1lnl.gov 
ABSTRACT. The segmental order and dynamics of polymer network chains in a filled, tri-modal silicone network have been studied by static ${ }^{1} \mathrm{H}$ Multiple Quantum (MQ) NMR methods to gain insight into the structure property relationships. The materials were synthesized with two different types of crosslinks, with functionalities of 4 and near 60 . The network chains were composed of distributions of high, low, and medium molecular weight chains. Crosslinking was accomplished by standard acid catalyzed reactions. MQ NMR methods have detected domains with residual dipolar couplings $\left(<\Omega_{\mathrm{d}}>\right)$ of near $4 \mathrm{kRad} / \mathrm{s}$ and $1 \mathrm{kRad} / \mathrm{s}$ assigned to (a) the shorter polymer chains and chains near the multifunctional $(\phi=60)$ crosslinking sites and to (b) the longer polymer chains far from these sites. Three structural variables were systematically varied and the mechanical properties and distributions of residual dipolar couplings measured in order to gain insight in to the network structural motifs that contribute significantly to the composite properties. The partitioning of and the average values of the residual dipolar couplings for the two domains were observed to be dependent on formulation variable and provided increased insight into the mechanical properties of these materials which are unavailable from swelling and spin-echo methods. The results of this study suggest that the domains with high crosslink density contribute significantly to the high strain modulus, while the low crosslink density domains do not. This is in agreement with theories and experimental studies on silicone bimodal networks over the last 20 years. In-situ MQ-NMR of swollen sample suggests that the networks deform non-affinely, in agreement with theory. The NMR experiments shown here provide increased ability to characterize multimodal networks of typical engineering silicone materials and to gain significant insight into structure-property relationships.

KEYWORDS. If you are submitting your paper to a journal that requires keywords, provide significant keywords to aid the reader in literature retrieval. 
INTRODUCTION. It is generally accepted that the bulk mechanical and relaxation properties of polymeric materials and their age dependence are controlled by the network structure. ${ }^{1-6}$ In order to interpret mechanical properties such as modulus, strength, and toughness and predict the time dependent changes in these properties, detailed characterization of the network structure and knowledge of the effect of structural changes on engineering properties has to be obtained. The degree and type of crosslinking, the molecular weight between crosslinks, the number of elastically ineffective chains (loops, dangling chain ends, sol-fraction), as well as filler content, surface properties, and interaction energies with the polymer network must be characterized. The required level of characterization can be difficult, however, to obtain for typical engineering silicone formulations which make use of complex distributions of network chain lengths, highly functional crosslinking sites, and inorganic reinforcing fillers to enhance the mechanical properties.

NMR methods have shown increasing ability to characterize elastomer network structure and heterogeneities and, in fact, have gained much attention in the last few decades for their ability to characterize changes in chemical composition and network structure non-destructively. ${ }^{7-22} \mathrm{~A}$ range of experimental methods have been used to investigate segmental dynamics in, for example, silicone based elastomeric materials, and in fact, the use of ${ }^{1} \mathrm{H}$ relaxometry has become quite standard. Unfortunately, standard echo based relaxation based methods have been shown to suffer from severe limitations. ${ }^{10,19-22}$ These include sensitivities to motional processes over many timescales, to susceptibility variations within the sample, and to polymer chain diffusion. In addition, the interpretation of the relaxometry data to extract knowledge of the network chain segmental dynamics and the network structure are strongly dependent on assumptions that are not broadly applicable. ${ }^{19}$ A number of methods have been developed to bypass these limitations and include the dipolar correlation effect on the stimulated echo, the Magic Echo, and ${ }^{2}$ H NMR lineshape analysis. ${ }^{12,14,17,18}$

Recently ${ }^{1} \mathrm{H}$ Multiple Quantum (MQ) methods have been applied to the problem of characterizing structural and dynamic processes in elastomeric systems and have shown much promise for such applications. ${ }^{15,16,19-29}$ Static ${ }^{1} \mathrm{H}$ Multiple Quantum NMR methods have been shown to quantitatively 
measure distributions in the residual dipolar couplings, $<\Omega_{\mathrm{d}}>$, in silicone materials. ${ }^{19-24}$ Access to such distributions is beyond the reach of spin-echo based approaches. In elastomeric materials, $<\Omega_{\mathrm{d}}>\mathrm{s}$ are the result of topological constraints interfering with fast reorientations on the NMR timescale that otherwise would be expected to average homonuclear dipolar couplings to zero. ${ }^{10}<\Omega_{\mathrm{d}}>$ s, in fact, have been shown to be quite sensitive to network and morphological changes and have been used to test theories of polymer structure, ordering, and dynamics. ${ }^{10,19-23}$ It has been reported that the characterization of the growth of multiple quantum coherences can provide detailed insight into silicone network structure by increasing the selectivity of the NMR experiment to the structure and dynamics most connected to the topology of the polymer network, including chain ordering at the surface of inorganic filler particles. $^{15,16,19-23}$. The MQ methods, in fact, have been shown to more accurately characterize the network structure than more traditional spin-echo based approaches which can over estimate the residual dipolar couplings due to the effects of magnetic susceptibilities and field gradients. ${ }^{19-22}$

We have employed recently developed MQ methods to investigate the structure-property relationships in a series of trimodal, endlinked filled-PDMS networks crosslinked with highly functional silane sites. The general enhancements of mechanical properties through the use of multimodal distributions of chain lengths and the use of highly functional crosslinking agents have been described elsewhere., ${ }^{4,6,30-34}$ The materials studied here are constructed from PolyDiMethylSiloxane (PDMS) chains of three average chain lengths, crosslinked with TetraPropoxySilane (TPS; functionality, $\phi$, of four) and PolyMethylHydrogenSilane (PMHS; $\phi=30-80$ ), using standard condensation reactions. ${ }^{35}$ Previous studies have demonstrated the ability of MQ NMR methods to characterize network structure in bimodal silicon networks, and in complex commercial silicone formulations. ${ }^{15-16,19-21}$ The former networks are relatively simple compared to the materials studied here and used only crosslinking sites with $\phi=3$ or 4 . The commercial silicones studied previously were proprietary formulations and thus specific correlations between chemical formulation and network structure could not be obtained. Our results clearly demonstrate that these MQ methods can provide key insight into highly complex silicone 
networks and can be used to gain insight into the structure-function relationships unavailable by other means.

\section{EXPERIMENTAL}

Materials: Model silicone networks were produced using standard Sn-octanoate catalyzed, endlinking silicone chemistry. ${ }^{35}$ The networks were constructed from a combination of hydroxyl-endlinked PDMS with three different average molecular weights [High Molecular Weight $(\mathrm{HMW}): \mathrm{M}_{\mathrm{n}}=13,600, \mathrm{M}_{\mathrm{w}}=$ 58,300; Medium Molecular Weight (MMW): $\mathrm{M}_{\mathrm{n}}=11,700, \mathrm{M}_{\mathrm{w}}=27,400$; Low Molecular Weight (LMW): $\mathrm{M}_{\mathrm{n}}=1,530, \mathrm{M}_{\mathrm{w}}=1,850$ ] and two different crosslinking units [TetraPropoxySilane (TPS): FW $=264 \mathrm{~g} / \mathrm{mol}, \phi=4$; and PolyMethylHydrogenSilane (PMHS) of four different molecular weights $\left(\mathrm{M}_{\mathrm{n}}=\right.$ $3,700, M_{w}=8,200, \phi=80 ; M_{n}=3,700, M_{w}=8,200, \phi=70 ; M_{n}=3,700, M_{w}=8,200, \phi=60 ; M_{n}=$ $\left.2,000, \mathrm{M}_{\mathrm{w}}=4,400, \phi=30\right)$. Here the functionality of the crosslinking sites, $\phi$, is the number of available sites per molecule for crosslilnking. In addition, DiPhenylMethylSilanol (DPMS: FW = 214 $\mathrm{g} / \mathrm{mol}, \phi=1$ ) was added as a blowing agent and low temperature modifier. All the above materials were obtained from NuSil [Carpenteria, CA].

The base resin was made by mixing all three hydroxyl-endlinked PDMS chains, diatomaceous earth filler [15 wt\%], TPS [5 wt\%], DPMS [5 wt\%], and PMHS [2-6 wt\%] with a mechanical mixer until homogeneous. Network foams were created by adding 5\% by weight Sn-octanoate catalyst to the base resin at room temperature and mixing for approximately 15 seconds. The catalyzed resin was then immediately poured into the mold, closed, and allowed to cure for a minimum of 15 minutes. The reaction of the silanol sites of the PDMS chains with the silane sites on the PMHS produces $\mathrm{H}_{2}$ which forms the pore structure as the network cures. The foamed network was then allowed to air cure at room temperature for a minimum of 16 hours followed by postcuring at $240{ }^{\circ} \mathrm{F}$ for 3 to 3.5 hours. The chemical species and an illustration of the resulting network are shown in Figure 1. GPC chromatograms of the three starting PDMS components are shown in Figure 2. 
Materials were created for a series of three studies: (1) The total weight of HO-PDMS-OH was kept the same, but the amount of the High MW chains was varied (essentially changing only the ratio of HMW to L and MMW chains, not the total amount PDMS in the network); (2) The proportions of the three chain lengths of PDMS were kept constant and the amount of PMHS $(\phi=60)$ was varied; and (3) the MW and thus length and functionality of the PMHS was varied. Compositions for all samples studied here are listed in Table 1.

To further classify the networks, the average stoichiometry was calculated. The stoichiometery number is the ratio of available silanol end-links to the number of crosslink sites. Ideal networks would have a stoichiometry near one. However, many complex engineering silicones are characterized by stoichiometry values far from one, as may be required to meet specific formulation and engineering compliance requirements. For example, in the formation of blown foams such as these, a balance needs to be maintained between reaction rate and stoichiometry. There is a need to ensure that the reaction progresses at a sufficient rate to generate $\mathrm{H}_{2}$ to a continuous pore structure, but not too rapid to generate a heterogeneous pore structure, and at the right rate to form a continuous network. Otherwise, a "good" foam might not be produced.

Methods: Swelling: Samples were weighed before and after swelling in Toluene and the percent change in volume upon swelling was calculated. The average crosslink density of the polymer network was then calculated by methods described elsewhere. ${ }^{13}$ Mechanical properties (load as a function of compressive strain) of these materials were measured on a Gilmore testing device.

${ }^{1}$ H NMR methods: Experiments were performed at $400.13 \mathrm{MHz}$ on a Bruker Avance 400 spectrometer using a Bruker TBI (HCX) $5 \mathrm{~mm}$ probe. In all cases, small $(0.1 \mathrm{~cm} \times 0.1 \mathrm{~cm} \times 0.1 \mathrm{~cm})$ squares of elastomer were cut from a larger piece and set in the portion of a $5 \mathrm{~mm}$ NMR tube that would be within the coil volume of the probe. Traditional ${ }^{1} \mathrm{H}$ Hahn-spin echo experiments ${ }^{7,10,36}$ were performed with a $90^{\circ}$ pulse lengths of $5.75 \mu \mathrm{s}$ and recycle delay time of $6 \mathrm{sec}$, and echo delays were varied from 0-30 ms. Echo intensity curves were plotted on a logarithmic scale and fit to a bi-exponential decay representing 
two separate relaxation processes:

$$
\text { E.I. }(\tau)=\mathrm{X}_{\text {short }} \exp \left(-2 \tau / \mathrm{T}_{2 \text { short }}\right)+\mathrm{X}_{\text {long }} \exp \left(-2 \tau / \mathrm{T}_{2 \text { long }}\right)
$$

where $X_{i}$ are the mole fractions of chains in each domain, $\tau$ the delay between the $90^{\circ}$ and $180^{\circ}$ pulses, and $T_{2, i}$ are the transverse relaxation time of each domain. The domains with the short $T_{2}$ are typically assigned to the polymer chains associated with the crosslinked network while the domains with the long $\mathrm{T}_{2}$ are assigned to the chains associated with the uncrosslinked, sol-fraction. ${ }^{11,13,14}$ For all the samples studied here, the amount of the sol-fraction ( $\mathrm{X}_{\text {long }}$ ) was found to be $4 \pm 2 \%$.

Multiple quantum NMR experiments were performed using the refocused multiple quantum excitation and reconversion pulse sequence shown in Figure 3. The phases of the reconversion sequence were cycled in $90^{\circ}$ steps with phase inversion on the observe pulse for coherence selections (the pulse sequence excites all even-multiple quantum coherences). CYCLOPS was then added to yield sixteen step phase cycle. ${ }^{37}$ As described in Saalwächter, the pulse sequence yields the total sum of the evenmultiple quantum coherences, dominated by the double quantum coherences, $\mathrm{S}_{\mathrm{mq} \cdot}{ }^{15,16,19-22}$ Pulse lengths of $5.75 \mu$ s were used with delay $\Delta_{1}$ and $\Delta_{2}$ equal to $4.7 \mu$ s and $5.8 \mu$ s respectively. The scaling factor, a, for these values is 0.655 . The effective excitation time was then calculated by $t_{\mathrm{e}}=\mathrm{t}^{*} \mathrm{a}$, where $\mathrm{t}=16^{*} \pi / 2$ $+8^{*} \Delta_{1}+8^{*} \Delta_{2} \cdot{ }^{19}$ Repeat experiments with longer delay times indicated that for these delays, no artifacts due to high duty cycle were observed. MQ growth experiments performed at temperatures of 300, 320, and $340 \mathrm{~K}$ were identical, indicating that the separation of timescales assumption was valid in these polymers. $^{19}$

The spectral intensities from the MQ pulse sequence, $S_{m q}(t)$, were then normalized with the use of a reference spectrum obtained by removing the alternating phases on the observe pulse, $\mathrm{S}_{\text {ref }}\left(\mathrm{t}_{\mathrm{e}}\right)$. The reference signal was then corrected by subtracting the long time decay component assigned to the solfraction of the polymer network, $\mathrm{S}_{\text {ref }}^{*}\left(\mathrm{t}_{\mathrm{e}}\right)=\mathrm{S}_{\text {ref }}\left(\mathrm{t}_{\mathrm{e}}\right)-\mathrm{S}_{\text {ref-long }}\left(\mathrm{t}_{\mathrm{e}}\right) .{ }^{19}$ The normalized multiple quantum integral was obtained by calculating the following for each effective excitation time, $\mathrm{t}_{\mathrm{e}}$,

$$
\mathrm{I}_{\mathrm{mq}}\left(\mathrm{t}_{\mathrm{e}}\right)=\mathrm{S}_{\mathrm{mq}}\left(\mathrm{t}_{\mathrm{e}}\right) /\left(\mathrm{S}_{\mathrm{mq}}\left(\mathrm{t}_{\mathrm{e}}\right)+\mathrm{S}_{\text {ref }}^{*}\left(\mathrm{t}_{\mathrm{e}}\right)\right)
$$


In the case of spins characterized by a dominant residual dipolar coupling, the multiple quantum growth curve is then described by

$$
\mathrm{I}_{\mathrm{mq}}\left(\mathrm{t}_{\mathrm{e}}\right)=\mathrm{A} *\left(1-\exp \left(-\mathrm{B}<\Omega_{\mathrm{d}}>^{2} \mathrm{te}_{\mathrm{e}}^{2}\right)\right.
$$

In cases where spins can be described by more than one residual dipolar coupling, as in the case of bimodal or phase separated network structures, the multiple quantum growth curves can be described by a summation of growth curves

$$
\mathrm{I}_{\mathrm{mq}}\left(\mathrm{t}_{\mathrm{e}}\right)=\Sigma \mathrm{A}_{\mathrm{i}}^{*} \mathrm{X}_{\mathrm{i}}^{*}\left(1-\exp \left(-\mathrm{B}_{\mathrm{i}}<\Omega_{\mathrm{d}}>_{\mathrm{i}}^{2} \mathrm{t}_{\mathrm{e}}^{2}\right)\right.
$$

where $X_{i}$ is the relative mole fraction of spins with $<\Omega_{d}>_{i}$ and $A_{i}$ and $B_{i}$ are pulse sequence and monomer specific constants - for a static second moment approximations: $\mathrm{A}_{\mathrm{i}}=0.5$ and $\mathrm{B}_{\mathrm{i}}=15.77 .{ }^{19}$

The relationship between the residual dipolar coupling and polymer structural variables has been described using the scale-invariant model and extensively described elsewhere. ${ }^{10,12,19,26,38}$ These studies have correlated the residual dipolar couplings to the dynamic order parameter, $\mathrm{S}_{\mathrm{b}}$, and to the number of statistical segments, $\mathrm{N}$, between constraints:

$$
\mathrm{S}_{\mathrm{b}}=\left[<\Omega_{\mathrm{d}}>/<\Omega_{\mathrm{d}}>_{\text {static }}\right] /<\mathrm{P}_{2}(\cos \alpha)>=3 \mathrm{r}^{2} / 5 \mathrm{~N}
$$

where $<\Omega_{\mathrm{d}}>_{\text {static }}$ is the dipolar coupling in the absence of motion (but pre-averaged by the fast motion of the methyl group) and equal to $8900 \mathrm{~Hz},\left\langle\mathrm{P}_{2}(\cos \alpha)>\right.$ is the time averaged second order Legendre polynomial of the angle between the dipolar vector and the chain axis (i.e. the angle between the chain axis and the $\mathrm{Si}-\mathrm{C}$ vector, taken here to be $90^{\circ}$ ), and $\mathrm{r}$ is the vector describing the deviation of the end-toend vector, $\mathbf{R}$, from that of the unperturbed melt, $\mathbf{R}_{\mathrm{o}}: \mathrm{r}=\mathbf{R} / \mathbf{R}_{\mathrm{o}}{ }^{39}$

Fitting and Regularization of Growth Curves: A two site fit of Equation 4 on the growth curve from 0-0.45 was performed in MatLab (Mathworks) and the results are presented under the heading "2Component Fit" in Table 2. Figure 4A shows a representative data curve, in solid diamonds, and the corresponding 2-site fit, in dashed light grey. Regularization of the buildup curves, also from $0-0.45$, was performed using the FTIKREG software. ${ }^{39}$ The probability distribution obtained from 
regularization is shown in Figure $\mathbf{4 B}$ as open diamonds. Using the program FitYK (http://www.unipress.waw.pl/fityk/), the first peak in the distributions was fit best with a split Gaussian function while the second peak was fit by a Gaussian as shown in Figure 4B.

\section{RESULTS AND DISCUSSION}

As mentioned above, three sets of samples were synthesized for this study: 1) samples with varying ratio of the HMW PDMS chains to LMW and MMW PDMS chains; 2) samples with varying amount of the highly functional crosslinking site PMHS; and 3) samples with varying molecular weight of the highly functional crosslinking site PMHS. These variables were chosen as likely contributors to changes in the mechanical properties of the materials. The compression stress-strain curve for three materials with varying amount of high molecular weight chains to lower molecular weight chains is shown in Figure 5. The stress-strain curves are typical of engineering silicones with initial elastic behavior followed by a plateau range of strains in which the required load does not significantly increase with compression. At high strains the behavior is again elastic as the stress dramatically increases as foam network reaches full density. The materials prepared here are approximately $30-40 \%$ porous, thus the load at $20 \%$ compression is due to compression of foam structure and differences between samples are due primarily to small differences in the porosity from sample to sample. At higher compressions, the foam approaches full density and the compression modulus reflects the properties of the network. For simplicity, in the following discussion, the load at three different degrees of compression $(22 \%, 47 \%$, 50\%, shown in Figure 5A as black diamonds, black squares, and open triangles) will be compared rather than the entire curve. These three points represent strains in the viscous plateau range and as the material approaches full density. Figure 6A-C shows these loads as a function of structural variable for the three sets of samples.

For the samples made varying the ratio of high to low molecular weight chains [Figure 6A], the load at low compressive strain decreases slightly from $200 \mathrm{kPa}$ with increasing HMW chains. The loads at the mid compressive strain (47\%) remain roughly constant at $600 \mathrm{kPa}$ until $\sim 84 \% \mathrm{HMW}$ chains where 
the required load begins to decrease for increased content of the HMW chains. The loads at high compressive strain (50\%) increase from $700 \mathrm{kPa}$ at a content of $77 \%$ to 800 at $84 \%$ and then decrease to $400 \mathrm{kPa}$ at $86.5 \%$. For the samples made with varying amounts of the high functionality $[\phi=60]$ crosslinking PMHS [Figure 6B], the loads at all compressive strains steadily increased as the amount of PMHS was increased from $2 \mathrm{wt} \%$ to $6 \mathrm{wt} \%$. As the degree of compression increases from $22 \%$ to $50 \%$ the slope of the data increases. For the samples made with increasing functionality of the PMHS site [Figure 6C], the loads at all compressive strains steadily increase with increased functionality. Again, the degree of increase for the different compressive strains increases with the compressive strain, though less severely than for the PMHS content study.

Non-stoichiometric networks imply a high amount of dangling chain ends, which may be expected to affect the material mechanical properties. However, we have observed no changes in the mechanical properties that could be directly attributed to the stoichiometric ratio. This is not necessarily surprising given that most of the highly functional junctions in the networks prepared here still have a significant fraction of chains branching off that can interact with network. Also, the molecular weights of the high and mid MW chains are well above the critical MW for entanglements $\left(\mathrm{M}_{\mathrm{e}} \sim 8100\right.$ to $\left.12000 \mathrm{~g} / \mathrm{mol}\right) .{ }^{5,19}$ As a result, they would be expected to contribute to the mechanical properties, although to a lesser degree than chemical crosslinks. $4,6,30$

The percent change in $1 / T_{2}$ (the sol-fraction remained constant within experimental error at $4 \pm 2 \%$ for all samples) as measured by spin-echo methods for the three studies are shown in Figure 6D-F. As the amount of the low crosslink density chains increased, $1 / \mathrm{T}_{2}$ remained constant, within error. As the amount of PMHS increased, $1 / \mathrm{T}_{2}$ increased; and as the MW of the PMHS increased, $1 / \mathrm{T}_{2}$ increased until $\phi=70$ then $1 / \mathrm{T} 2$ is lower for $\phi=80$. The spin echo curves here do not show any evidence of the mixedGaussian/Exponential decay shapes typical for crosslinked silicones and did not show any evidence for more than two components (the network component $\left(\mathrm{T}_{2} \sim 1.5 \mathrm{~ms}\right)$ and the sol-fraction $\left.\left(\mathrm{T}_{2} \sim 12 \mathrm{~ms}\right)\right)^{10}$

Crosslink density was measured indirectly by the mass increase upon swelling in toluene. The 
percent change in crosslink density as measured by percent increase in weight from swelling in toluene are shown in Figure 6G-I. The crosslink density was observed to decrease to a small extent with increased amount of high molecular weight chains. For samples prepared with varying amounts of PMHS, it was observed that the amount of toluene swelling decreased with an increase of PMHS. For samples with increasing functionality of the PMHS crosslinker, the crosslink density steadily increased, as would be expected with an increase in the number of chemical crosslink junctions. For all samples the trends observed in the mechanical properties, the swelling, and the spin-echo experiments are similar. The data shown here underlines the need for characterization tools that provide insight into domain distributions. While average crosslink density can be estimated from these methods no characterization of changes in distributions between domains can be obtained. Such changes in domain size or distribution can be key contributors to mechanical property changes.

The MQ growth curve obtained for a representative sample (LK3626) is shown in Figure 4A. Fits to one $<\Omega_{\mathrm{d}}>$ were unable to acceptably fit the growth curve for any sample studied here. In order to obtain an acceptable fit, a growth curve obtained from a superposition of two growth curves was necessary. A bimodal growth curve derived from a domain with $\left\langle\Omega_{\mathrm{d}}>_{\text {low }}\right.$ of near $1200 \mathrm{Rad} / \mathrm{s}$ (population $65 \%$ ) and a domain with $<\Omega_{\mathrm{d}}>_{\text {high }}$ of near $6900 \mathrm{Rad} / \mathrm{s}$ (population $35 \%$ ) was obtained from a least squares fit of equation 4 is indicated by the dashed line in Figure 4A. The MQ growth curves for each domain on it's own are also shown in Figure 4A. Previous studies have observed such bimodal growth curves and they have been assigned to network domains with low crosslink densities and high crosslink densities. These can be due to heterogeneous network structure or interactions with the filler interface. ${ }^{15,}{ }^{19}$ For these samples, we assign the $<\Omega_{\mathrm{d}}>_{\text {low }}$ domain to high and mid molecular weight network chains far from the highly functional PMHS crosslinking sites, and the $\left.<\Omega_{\mathrm{d}}\right\rangle_{\text {high }}$ domain to the low molecular weight chains and the chains near the PMHS highly functional crosslinking species. These assignments are based on the following justifications: the filler content is low (15 wt.\% of diatomaceous earth, Surface Area $\left.\sim 10 \mathrm{~m}^{2} / \mathrm{g}\right)$, thus the amount of adsorbed chains would be expected to be negligibly small $(<1 \%)$. 
The populations derived from the bimodal model, $65 \%$ low crosslink density chains; $35 \%$ high crosslink density chains, are very similar to those derived from the starting materials: $16.5 \mathrm{wt} \%$ Low MW chains, $13.9 \mathrm{wt} \%$ Mid MW chains, $41.6 \mathrm{wt} \%$ high MW chains; neglecting the contribution of chains near the PMHS crosslinking sites results in a prediction of $77 \%$ of ${ }^{1} \mathrm{H}$ spins in the $\left\langle\Omega_{\mathrm{d}}>_{\text {low }}\right.$ and $23 \%$ in the $\left.<\Omega_{\mathrm{d}}\right\rangle_{\text {high }}$ domain. Taking the extra $12 \%$ in the $\left\langle\Omega_{\mathrm{d}}\right\rangle_{\text {high }}$ domain to be monomers of the polymer chains attached to the PMHS crosslinking sites, we predict that the first four monomers of each chain are constrained such that their residual dipolar coupling increases to values similar to $\left\langle\Omega_{\mathrm{d}}\right\rangle_{\text {high}}$.

Results of the discrete two site fit to equation 4 are listed in Table 2 and plotted as a function of structural variable changed in Figure 7. For the set of samples prepared with varying amounts of high MW chains to low MW chains, $\left\langle\Omega_{\mathrm{d}}>_{\text {low }}\right.$ remained constant at $\sim 1 \mathrm{kRad} / \mathrm{s}$ while $\left\langle\Omega_{\mathrm{d}}\right\rangle_{\text {high }}$ increased steadily from $4.5 \mathrm{kRad} / \mathrm{s}$ to $5.5 \mathrm{kRad} / \mathrm{s}$. The percentage of chains in the $\left\langle\Omega_{\mathrm{d}}>_{\text {low }}\right.$ domain also increased steadily from $63 \%$ to $73 \%$. For the series prepared with increasing PMHS content, again $<\Omega_{\mathbb{d}}>_{\text {low }}$ remained constant at $\sim 1 \mathrm{kRad} / \mathrm{s}$ while $<\Omega_{\mathrm{d}}>_{\text {high }}$ increased from $4 \mathrm{kRad} / \mathrm{s}$ to $7 \mathrm{kRad} / \mathrm{s}$ and the percentage in $\left\langle\Omega_{\mathrm{d}}>_{\text {low }}\right.$ decreased from $70 \%$ to $65 \%$. In the series of samples prepared with increasing functionality of the PMHS crosslinking agent, $<\Omega_{\mathrm{d}}>_{\text {low }}$ remained constant at $\left.1 \mathrm{kRad} / \mathrm{s},<\Omega_{\mathrm{d}}\right\rangle_{\text {high }}$ decreased from 7 $\mathrm{kRad} / \mathrm{s}$ to $5 \mathrm{kRad} / \mathrm{s}$, and the population in $\left\langle\Omega_{\mathrm{d}}\right\rangle_{\text {low }}$ decreased from $75 \%$ to $55 \%$.

MQ growth curves as obtained here can also be described by distributions of residual dipolar couplings. ${ }^{19}$ Attempts to fit the growth curves obtained in this study to a single Gaussian site were unacceptable in all cases and are not presented. As described here in the Experimental section and described by Saalwächter, the MQ growth curves can also be analyzed by regularization. ${ }^{19}$ The result from FTIKREG regularization of the LK3626 sample is shown in Figure 4B and shows two broad distributions of residual dipolar couplings centered near $1 \mathrm{kRad} / \mathrm{s}$ and $4 \mathrm{kRad} / \mathrm{s}$, similar to the $\left\langle\Omega_{\mathrm{d}}>\right.$ obtained from the two site fits. The result of the FTIKREG regularization were then fit to overlapping Gaussian peaks as described in the Experimental section and the width and relative populations of the 
two sites were obtained with $\mathrm{X}_{\text {low }}=89 \%, \sigma_{\text {low }}=0.48$, and $\sigma_{\text {high }}=2.05$. The distributions of $<\Omega_{\mathrm{d}}>$ s obtained through regularization indicate that, in general, two Gaussian functions can describe the build up curve as shown in Figure 4B. The technique of regularization followed by peak fitting also proved to be a far more efficient than fitting multiple Gaussian functions with MatLab. The results of regularization followed by deconvolution are listed in Table $\mathbf{2}$ and plotted as a function of structural variable in

\section{Figure 8.}

Figure 8Ai shows the change in $\left\langle\Omega_{\mathrm{d}}\right\rangle_{\text {low }}$ and $<\Omega_{\mathrm{d}}>_{\text {high }}$ with increasing content of the high molecular weight chains and Figure 8Aii shows the change in the partitioning between the two sites as a function of increasing High MW PDMS chain content. For this series of samples, we observed that, as the PDMS content was increased, $<\Omega_{\mathrm{d}}>_{\text {low }}$ remained relatively constant and the number of chains that could be described by $<\Omega_{\mathrm{d}}>_{\text {low }}$ was also constant. The width in the distributions of $<\Omega_{\mathrm{d}}>_{\text {high }}$ and $\left.<\Omega_{\mathrm{d}}\right\rangle_{\text {low }}$ decreased generally as the number of HMW chains increased with the width in the distribution of $<\Omega_{\mathrm{d}}>_{\text {high }}$ decreasing to a greater extent (see Table 2). The results of the deconvolution of the $<\Omega_{\mathrm{d}}>$ distributions for the samples prepared with increasing PMHS content are presented in Figure 8Bi and 8Bii. As the PMHS content was increased, $\left\langle\Omega_{\mathrm{d}}>_{\text {low }}\right.$ remained fairly constant at $\sim 1 \mathrm{kRad} / \mathrm{s}$, while an increase in $<\Omega_{\mathrm{d}}>_{\text {high }}$ from $4.2 \mathrm{kRad} / \mathrm{s}$ to $6 \mathrm{kRad} / \mathrm{s}$ and the amount of protons with $<\Omega_{\mathrm{d}}>_{\text {low }}$ remained constant. The width in the distributions of $\left\langle\Omega_{\mathrm{d}}\right\rangle_{\text {high }}$ and $\left\langle\Omega_{\mathrm{d}}\right\rangle_{\text {low }}$ were observed to increase for this series of samples as the PMHS content was increased, again with $<\Omega_{\mathrm{d}}>_{\text {high }}$ changing to a higher degree than $<\Omega_{\mathrm{d}}>_{\text {low }}$ (see Table 2). The results of the deconvolution of the $<\Omega_{\mathrm{d}}>$ distributions for the samples prepared with increasing PMHS molecular weight and functionality are presented in Figure 8Ci and 8Cii. As the MW of the PMHS increased, the average $<\Omega_{\mathrm{d}}>_{\text {high }}$ increased from $3 \mathrm{kRad} / \mathrm{s}$ to $\sim 4 \mathrm{kRad} / \mathrm{s}$ (the sample with $\phi=60$ was found to be much higher at $6.2 \mathrm{kRad} / \mathrm{s}$ ), the $<\Omega_{\mathrm{d}}>_{\text {low }}$ remained constant at 1 $\mathrm{kRad} / \mathrm{s}$ and the population in $\left\langle\Omega_{\mathrm{d}}>_{\text {low }}\right.$ decreased from $\sim 95 \%$ to $83 \%$. The widths of the distributions in both $<\Omega_{\mathrm{d}}>_{\text {high }}$ and $<\Omega_{\mathrm{d}}>_{\text {low }}$ were observed to remain constant for the most part with changes in the MW 
of the PHMS component, with the exception of the LK3626 sample with $\phi=60$. For this sample, $<\Omega_{\mathrm{d}}>_{\text {high }}$ and the width of $<\Omega_{\mathrm{d}}>_{\text {high }}$ were observed to be higher than other samples in this set, though in line with the trends observed in the PMHS content study. It is unknown at this time what is the cause of this discrepancy, but could be due to processing differences in the MW study.

The values of $\left\langle\Omega_{\mathrm{d}}>\right.$ obtained from regularization are all slightly lower than those obtained with the two-component fit, while the percentages of $\left\langle\Omega_{\mathrm{d}}\right\rangle_{\text {low }}$ are about $20 \%$ higher. However, comparisons of the FTIKREG data in Figure 8 with the two component fits in Figure 7 show that the trends remain similar. One exception to this is the PDMS Content Study in which no trends, either in the values of $<\Omega_{\mathrm{d}}>$ or in the percentages of the components, are seen in Figure 8Ai and 8Aii. For the PMHS content study the higher $<\Omega_{d}>$ increases with increasing amounts of PMHS, shown in Figure 8Bi, which is consistent with the previous two-component results. For the PMHS MW Study Figure 8Cii shows a distinct trend of a decrease in the percentage of sites characterized by the lower $\left\langle\Omega_{\mathrm{d}}\right\rangle$ with increasing molecular weight. However, the trend seen in the 2-site fitting, where the higher $\left\langle\Omega_{\mathrm{d}}>\right.$ decreased, was not seen in the distributions deconvolutions.

The values of the residual dipolar couplings obtained in this study compare well with values obtained elsewhere given the differences in network structure. ${ }^{25}$ From equation 5 , the dynamic order parameters observed here are $\mathrm{S}_{\mathrm{b} \text {,low }} \sim 0.035$ and $\mathrm{S}_{\mathrm{b}, \text { high }} \sim 0.16$. These values lead to average $\mathrm{N}$, number of NMRactive submolecules, of 17 and 4, respectively. Previous studies have estimated the number of monomers per statistically relevant submolecule to be $\sim 5.85^{41}$ This would estimate molecular weights between crosslinks of $\mathrm{MW}_{\text {low }} \sim 7500 \mathrm{~g} / \mathrm{mol}$ and $\mathrm{MW}_{\text {high }} \sim 1600 \mathrm{~g} / \mathrm{mol} . \mathrm{MW}_{\text {low }}$ is similar to the estimated MW between entanglements of 8100 - $12000 \mathrm{~g} / \mathrm{mol}$ and suggests that the segmental order in this domain is determined not by the chemical crosslinks, but by the entanglements. The $\mathrm{MW}_{\mathrm{high}}$ is in general agreement with the value of the short chain constituent starting material.

For all samples studied here, the MQ NMR approach (whether via descrete two site fit or FTIKREG regularization) provides additional insight into the segmental dynamics and segmental ordering that the 
swelling and the spin-echo methods do not. As mentioned above, the swelling and spin-echo approaches do not allow in this series of samples to individually characterize the domains with low and high crosslink densities and provide only a bulk average measure of the crosslink density. The MQ NMR methods, on the other hand, have allowed us to measure the residual dipolar couplings in both domains selectively. These measurements provide key insight into the segmental ordering (see equation 5) and provide additional insight into the contributions of each domain to the mechanical properties. As shown in Figure 5 and 6, the modulus at low \% compression is fairly constant for all samples while the modulus at high \% compression is very sensitive to the synthetic variables. The MQ results on these samples indicate that the residual dipolar coupling of the domains with low crosslink density are fairly unchanged with changes in the composition of the polymer network while the residual dipolar couplings of the domains with high crosslink density are strongly correlated with the compositional variables. Comparing the compression results with the results of the MQ NMR studies indicate that the material mechanical properties at high compression are influenced by the segmental structure of the domains with high crosslink density, as has been suggested in previous studies ${ }^{32-34}$.

Numerous theories have been developed to predict the heterogeneous "non-affine" deformation of bimodal networks under strain. ${ }^{32-34}$ Our experimental setup did not allow for controllable in-situ MQ NMR analysis of the materials studied here under compressive strain. Saalwächter recently showed that in situ-MQ NMR is conveniently performed on samples strained from solvent swelling. ${ }^{21}$ In that study of a model bimodal network, it was shown that the individual domains respond heterogeneously to the swelling strain, with both $\left\langle\Omega_{\mathrm{d}}\right\rangle_{\text {high }}$ and $\left\langle\Omega_{\mathrm{d}}\right\rangle_{\text {low }}$ increasing and the distributions $\sigma_{\text {low }}$ and $\sigma_{\text {high }}$ broadening. ${ }^{21}$ The MQ-NMR growth curves and the regularization of those growth curves for sample LK3626, unswollen and swollen in $d_{6}$-toluene, is shown in Figure 9. Similar to Saalwächter's results, the data shown here indicates that upon swelling, the segmental order increases, as can be seen from the increased growth rate of the MQ signal. The deconvolution of these curves also indicates the segmental order of the low crosslink density, $\left.<\Omega_{\mathrm{d}}\right\rangle_{\text {low }}$, domains increases upon swelling from $\sim 1 \mathrm{kRad} / \mathrm{s}$ to $\sim 1.5$ 
$\mathrm{kRad} / \mathrm{s}$ while broadening significantly. The high crosslink density domain, on the other hand was observed to essentially broaden sufficiently to be indistinguishable from the high $<\Omega_{\mathrm{d}}>$ tail of the $<\Omega_{\mathrm{d}}>_{\text {low }}$ domain.

\section{CONCLUSIONS}

The segmental order and dynamics of polymer network chains in a tri-modal silicone network have been studied by static ${ }^{1} \mathrm{H}$ MQ-NMR methods. The MQ-NMR methods have allowed for the quantitation of chains in domains of high and low crosslink density comparable to the concentrations expected from the synthetic starting materials. Three structural variables were systematically varied and the mechanical properties and distributions of residual dipolar couplings measured in order to gain insight in to the network structural motifs that contribute significantly to the composite properties. The results of this study suggest that the domains with high crosslink density contribute significantly to the high strain modulus, while the low crosslink density domains do not. This is in agreement with theories and experimental studies on silicone bimodal networks over the last 20 years. In-situ MQ-NMR of swollen

sample suggests that the networks deform non-affinely, in agreement with theory. The NMR experiments shown here provide increased ability to characterize multimodal networks of typical engineering silicone materials and to gain significant insight into structure-property relationships. These tools are of particular value for studying aged, degraded, or unknown samples for which a priory insight in to the network structure is unavailable.

ACKNOWLEDGMENT. This work was performed under the auspices of the U.S. Department of Energy by the Lawrence Livermore National Laboratory under contract \# W-7405-ENG-48. The authors would like to thank Seth Gleiman and Jim Schnieder for their assistance in synthesis, Ed Fuller for GPC analysis of raw materials, and Kay Saalwächter for helpful discussions. Part of this work was supported by the LLNL Laboratory Directed Research and Development (LDRD) program (tracking 
number: 06-SI-005). 


\section{REFERENCES}

1. Flory, P. J., Principles of Polymer Chemistry, Cornell University Press, Ithaca, New York (1953).

2. Bicerano, J. Prediction of Polymer Properties, $3^{\text {rd }}$ Edition, Marcell-Dekker, New York 2002

3. Van Krevelen, D. W., Properties of Polymers, $3^{\text {rd }}$ Edition, Elsevier, Amsterdam, 1997.

4. Larsen, A. L.; Hansen, K.; Sommer-Larsen, P.; Hassager, O.; Bach, A.; Ndoni, S.; Jorgensen, M., Macromolecules, 2003, 36, 10063-10070.

5. $\mathrm{M}_{\mathrm{e}}$ : J. T. Seitz, J. Appl. Poly. Sci. 49, 1331-1351 (1993)

6. Andrady, A L; Llorente, M A; Sharaf, MA; Rahalkar, R. R.; Mark, J. E., J. Appl. Poly. Sci. 26, 1829-1836 (1981).

7. Bovey, F. A., NMR of polymers Academic San Diego, CA:1996

8. Schmidt-Rohr, K; Spiess, H. W. Multidimensional solid-state NMR and polymers Academic San Diego, CA:1994

9. Ando, I.; Asakura, T. Solid State NMR of Polymers Elsevier Science, London 1998

10. Cohen-Addad, J. P., Prog NMR Spect 1993; 25:1.

11. Gronski, W.; Hoffmann, U., Simon, G., Wutzler, A., Straube, E. Rubber Chem. Tech 1992; 65 63.

12. Grinberg, F.; Kimmich, R.; Moller, M.; Molenberg, A., J Chem Phys 1996; 105: 9657.

13. Chien, A.; Maxwell, R. S.; Chambers, D.; Balazs, B; LeMay, J., J Rad Phys Chem 2000; 59(5-6): 493. 
14. Maxwell, R. S.; Balazs, B, J Chem Phys 2002; 116: 10492.

15. Maxwell, R. S.; Chinn, S. C.; ect, Macromolecules 2005.

16. Chinn, S. C.; Poly. Deg. Stab. 2006

17. Jagadeesh, B., Demco, D. E., Blumich, B., Chem. Phys. Let. 2004, 393, 416.

18. Sotta, P.; Deloche, B.; Macromolecules 1990, 23, 1999-2007.

19. Saalwächter, K.; Herrero, B. ; Lopez-Manchado, M. A., Macromolecules, 2005, 28, 96509660.

20. Saalwächter, K. ; Kleinschmidt, Sommer, J-U., Macromolecules, 2004, 37, 8556-8568.

21. Saalwächter, K.; Ziegler, P.; Spyckerelle, O. ; Haidar, H.; Vidal, A., Sommer, J-U. J Chem. Phys. 2003; 119 (6): 3468-3482.

22. Saalwächter, K., J Chem Phys 2004; 120(1):454.

23. Wang, M.; Bertmer, M.; Demco, D. E.; Blumich, B.; Litvinov, V. M.; Barthel, H., Macromolecules 2003; 36: 4411-4413.

24. Fechete, R. ; Demco, D. E. ; Blumich, B., J Mag Res 2004; 169(1):19.

25. Friedrich, U.; Schnell, I.; Demco, D. E.; Spiess, H. W., Chem. Phys. Lett. 1998, $285,49$.

26. M. Schneider, M.; Gasper, L., Demco, D. E., Blumich, B., J Chem Phys 1999; 111, 402.

27. Graf, R.; Heuer, A.; Spiess, H. W., Phys. Rev. Lett., 1998; 805738.

28. Graf, R.; Demco, D. E;, Hafner, S.; Spiess, H. W., Solid State NMR, 1998; 12: 139.

29. Fechete, R.; Demco, D. E.; Blumich, B., Macromolecules 2002 ; 35: 6083.

30. Gottlieb, M; Macoscko, CW; Benjamin, GS; Meyers, KO; Merrill, EW, Macromolecules 
1981, 14, 1039-46.

31. Meyers, KO; Bye, ML; Merrill, EW, Macromolecules 198013 1045-1053.

32. Mark J. E. Macromolecules 1984172924

33. Mark, J. E., Acc. Chem. Res. 1994, 27, 271-278.

34. Mark, J. E., Adv. Poly. Sci., 1984, 65, 136-176.

35. Brook, M. A.; Silicon in Organic, Organometallic, and Polymer Chemistry, John Wiley \& Sons, New York, 2000.

36. Mehring, M., Principles of High Resolution NMR in Solids, Springer-Verlag, Berlin, 1983.

37. Ernst, R. R.. Bodenhausen, G.; Wokaun, A., Principles of Nuclear Magnetic Resonance in One and Two Dimensions, New York; Oxford University Press; 1987.

38. Callaghan, P. T.; Samulski, E. T.; Macromolecules 2000, 33, 3795-3802

39. "Fast Tikhonov Regularization (FTIKREG) (C Freiburger Materialforschunszentrum F.M.F., by J. Honerkamp and J. Weese.; Weese, J.; Comput. Phys. Commun. 1992, 69, 99-

40. Kuhn, W.; Grün, F. Kolloid-Z. 1942, 101, 248 
Gjersing, et al.

MQ-NMR non-stoichiometric PDMS networks

\section{TABLES}

Table 1. Composition of foam elastomers studies here. In addition, all samples were made from 15 wt.\% diatomaceous earth, 5 wt.\% TPS, and 5 wt.\% DPMS as described above. DP $=$ number of functional sites.

\begin{tabular}{|c|c|c|c|c|c|c|c|c|c|c|c|c|}
\hline & \multicolumn{4}{|c|}{ PDMS Content Study } & \multicolumn{5}{|c|}{ PMHS Content Study } & \multicolumn{3}{|c|}{ PMHS MW study } \\
\hline Ingredients & sX4 & SX462 & SX464 & SX466 & sX2 & SX3.5 & sX4 & SX4.5 & LK3626 & $\begin{array}{l}\text { LK } \\
\text { short }\end{array}$ & LKDC & LKUCT \\
\hline LMW-PDMS (wt.\%) & 17.0 & 12.0 & 10.0 & 8.0 & 17.4 & 17.1 & 17.0 & 16.8 & 16.5 & 16.5 & 16.5 & 16.5 \\
\hline MMW-PDMS (wt.\%) & 14.3 & 15.5 & 16.0 & 16.5 & 14.6 & 14.4 & 14.3 & 14.2 & 13.9 & 13.9 & 13.9 & 13.9 \\
\hline HMW-PDMS (wt.\%) & 42.8 & 46.5 & 48.0 & 49.5 & 43.9 & 43.1 & 42.8 & 42.5 & 41.6 & 41.6 & 41.6 & 41.6 \\
\hline $\begin{array}{l}\text { \%HMW in total } \\
\text { PMDS content }\end{array}$ & 77.1 & 83.8 & 86.5 & 89.2 & 77.1 & 77.1 & 77.1 & 77.1 & 77.1 & 77.1 & 77.1 & 77.1 \\
\hline PMHS (wt.\%) & 4.0 & 4.0 & 4.0 & 4.0 & 2.0 & 3.5 & 4.0 & 4.5 & 6.0 & 6.0 & 6.0 & 6.0 \\
\hline $\begin{array}{c}\text { Stoichiometric } \\
\text { Ratio } \\
\text { SiH/SiOH }\end{array}$ & 1.7 & 1.9 & 2 & 2.1 & 1.1 & 1.6 & 1.7 & 1.9 & 2.3 & 2.3 & 2.3 & 2.3 \\
\hline PMHS (DP) & 60 & 60 & 60 & 60 & 60 & 60 & 60 & 60 & 60 & 30 & 70 & 80 \\
\hline PMHS (Mw g/mol) & 8200 & 8200 & 8200 & 8200 & 8200 & 8200 & 8200 & 8200 & 8200 & 4400 & 10300 & 16000 \\
\hline
\end{tabular}


Gjersing, et al.

Table 2. Results of analysis of ${ }^{1} \mathrm{H}$ spin-echo and ${ }^{1} \mathrm{H}$ Multiple Quantum build-up curves for samples studied here. DP = number of functional sites.

\begin{tabular}{|c|c|c|c|c|c|c|c|c|c|c|c|c|c|}
\hline \multirow[b]{2}{*}{ Study } & \multirow[b]{2}{*}{ Sample } & \multirow[b]{2}{*}{$\begin{array}{c}\% \\
\text { PMHS }\end{array}$} & \multirow[b]{2}{*}{$\begin{array}{c}\text { PMHS } \\
\text { MW } \\
\text { (DP) }\end{array}$} & \multirow[b]{2}{*}{$\begin{array}{c}\% \\
\text { HMW } \\
\text { PDMS }\end{array}$} & \multirow[b]{2}{*}{$\begin{array}{c}\mathrm{T}_{2} \\
(\mathrm{~ms})\end{array}$} & \multicolumn{3}{|c|}{ 2-Component Fit } & \multicolumn{5}{|c|}{ FTIKREG Distribution Deconvolution } \\
\hline & & & & & & $\begin{array}{l}<\Omega_{\mathrm{d}}>\text { low } \\
(\mathrm{kRad} / \mathrm{s})\end{array}$ & $\begin{array}{l}<\Omega_{\mathrm{d}}>\text { high } \\
(\mathrm{kRad} / \mathrm{s})\end{array}$ & X.low & $\begin{array}{l}<\Omega_{\mathrm{d}}>\text { low } \\
(\mathrm{kRad} / \mathrm{s})\end{array}$ & $\begin{array}{l}<\Omega_{\mathrm{d}}>\text { high } \\
(\mathrm{kRad} / \mathrm{s})\end{array}$ & $\sigma^{\text {low }}$ & $\sigma^{\text {high }}$ & $\mathrm{X}_{\text {low }}$ \\
\hline \multirow{4}{*}{ 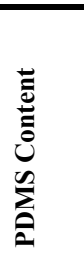 } & SX4 & 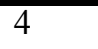 & 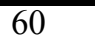 & $\overline{777.1}$ & 1.61 & 1.00 & "4.64 & 0.628 & $\overline{0.819}$ & $\overline{3.74}$ & 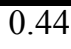 & 1.22 & 0.922 \\
\hline & SX462 & 4 & 60 & 83.8 & 1.61 & 1.09 & 5.14 & 0.689 & 0.916 & 4.57 & 0.37 & 0.79 & 0.914 \\
\hline & SX464 & 4 & 60 & 86.5 & 1.66 & 1.14 & 5.07 & 0.706 & 0.933 & 3.92 & 0.38 & 0.57 & 0.933 \\
\hline & SX466 & 4 & 60 & 89.2 & 1.66 & 1.06 & 5.32 & 0.727 & 0.878 & 4.28 & 0.37 & 0.74 & 0.920 \\
\hline \multirow{5}{*}{ 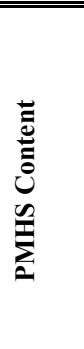 } & SX2 & 2 & 60 & 77.1 & 1.73 & 1.04 & $\overline{3.81}$ & 0.695 & 0.917 & 4.26 & 0.38 & 1.42 & 0.904 \\
\hline & SX3.5 & 3.5 & 60 & 77.1 & 1.60 & 1.17 & 5.23 & 0.698 & 0.904 & 5.49 & 0.39 & 1.47 & 0.894 \\
\hline & SX4 & 4 & 60 & 77.1 & 1.61 & 1.00 & 4.64 & 0.657 & 0.727 & 5.27 & 0.48 & 2.13 & 0.905 \\
\hline & SX4.5 & 4.5 & 60 & 77.1 & 1.55 & 1.08 & 5.07 & 0.665 & 0.946 & 5.55 & 0.43 & 2.42 & 0.873 \\
\hline & LK3626 & 6 & 60 & 77.1 & 1.44 & 1.18 & 6.86 & 0.649 & 0.965 & 6.24 & 0.48 & 2.05 & 0.892 \\
\hline \multirow{4}{*}{ 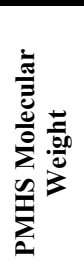 } & "LK(short) & $\overline{66}$ & 30 & $\overline{777.1}$ & 1.53 & 1.19 & 7.29 & 0.731 & 0.980 & 3.07 & 0.52 & 0.83 & 0.956 \\
\hline & LK3626 & 6 & 60 & 77.1 & 1.44 & 1.18 & 6.84 & 0.648 & 0.965 & 6.24 & 0.48 & 2.05 & 0.892 \\
\hline & $\mathrm{LK}(\mathrm{DC})$ & 6 & 70 & 77.1 & 1.32 & 1.14 & 5.61 & 0.580 & 0.942 & 3.93 & 0.46 & 0.90 & 0.877 \\
\hline & $\overline{\mathrm{LK}(\mathrm{UCT})}$ & 6 & 80 & 77.1 & 1.46 & 0.97 & 5.24 & 0.558 & 0.780 & 3.63 & 0.36 & 0.94 & 0.838 \\
\hline
\end{tabular}


Table 3. Results of deconvolution of MQ NMR experiments on pristine and swollen LK3626 sample.

\begin{tabular}{|c|c|c|c|c|c|c|c|c|c|}
\hline & \multicolumn{3}{|c|}{ 2-Component Fit } & \multicolumn{6}{|c|}{ FTIKREG Distribution Deconvolution } \\
\hline & $\begin{array}{l}<\Omega_{\mathrm{d}}>\text { low } \\
(\mathrm{kRad} / \mathrm{s})\end{array}$ & $\begin{array}{l}<\Omega_{\mathrm{d}}>\mathrm{h} \text { high } \\
(\mathrm{kRad} / \mathrm{s})\end{array}$ & $\mathrm{X}_{\text {low }}$ & $\begin{array}{l}<\Omega_{\mathrm{d}}>\text { low } \\
(\mathrm{kRad} / \mathrm{s})\end{array}$ & $\begin{array}{l}<\Omega_{\mathrm{d}}>\text { high } \\
(\mathrm{kRad} / \mathrm{s})\end{array}$ & $\sigma^{\text {Iow }}$ & $\sigma^{\text {mgn }}$ & $\mathrm{X}_{\mathrm{low}}$ & $\begin{array}{l}<\Omega_{\mathrm{d}}>_{\text {total }} \\
(\mathrm{kRad} / \mathrm{s})\end{array}$ \\
\hline Dry & 1.060 & 5.317 & 0.727 & 0.878 & 4.279 & 0.365 & 0.739 & 0.920 & 1.15 \\
\hline $\begin{array}{l}\text { Swollen in } \\
\text { toluene- } \mathrm{d}_{6}\end{array}$ & 1.377 & 5.506 & 0.606 & 1.200 & 3.510 & 0.688 & 1.223 & 0.925 & 1.37 \\
\hline
\end{tabular}




\section{FIGURE CAPTIONS}

Figure 1. Illustration of the network structure and the starting materials used to formulate the networks studied here. Foams were prepared and characterized with varying amounts of PDMS with three MW distributions, with varying amounts of PMHS, and with PMHS with varying numbers of functional crosslinking sites, $\mathrm{n}$.

Figure 2. Gel-Permeation Chromatography traces for the three starting PDMS polymers used to generate the networks studied here. (A) High molecular weight between crosslinks component; (B) medium molecular weight between crosslinks component; (C) low molecular weight between crosslinks component.

Figure 3. (A) ${ }^{1} \mathrm{H}$ MQ Pulse Sequence used in this study. The number of pulse trains, $\mathrm{n}_{\mathrm{c}}$, was incremented to generate growth curves. Phasing of the detection pulse was alternated to generate the reference curve. The raw growth curve and the reference data set were combined as discussed in the experimental section to generate growth curves that are dependent on crosslink density, as shown in (B).

Figure 4. A) MQ growth curve for pristine LK3626 (diamonds) with bi-exponential fit (dashed line). Also shown are the normalized growth curves for the two domains that contribute to the bi-exponential fit. (B) Distribution of residual dipolar couplings $\left\langle\Omega_{\mathrm{d}}>\right.$ obtained from FTIKREG regularization of the buildup curve in (A). Solid lines are the fits of Gaussian line shapes to the two overlapping distributions. Dashed line is the overall fit obtained by summing the two Gaussian distributions.

Figure 5. Loads required to reach given compressive strain for the materials studied here: (A) stressstrain curves for three samples in the HMW content study (solid: 83.9 wt.\%; dashed: 86.5 wt.\%; dotted: 89.2 wt. $\%$ ) with compressions of $22 \%, 47 \%$, and 50\% shown as diamonds, squares, and triangles, respectively.

Figure 6. Results of load retention testing (A-C), spin-echo (D-F) and swelling (G-I) analysis of the samples studied here. (A) load at the indicated compressive strains for samples synthesized with varying amounts of high molecular weight vs low molecular weight chains; (B) load at indicated compressive 
strains for samples synthesized with varying amounts of the highly functional crosslinking site PMHS; and (C) load at the indicated compressive strains for samples synthesized with the MW of the PMHS crosslinking chains increased. (D-F) results of analysis of spin-echo decay curves for same samples. (GI) \% increase in mass after swelling in toluene for same samples in (A-C)

Figure 7. Results of deconvolution of MQ growth curves for all samples studied here to equation $\{4\}$ with two sites plotted as a function of synthesis variable. $\left\langle\Omega_{\mathrm{d}}\right\rangle_{\text {high }}$ is the PDMS chains with high crosslink density, while $\left\langle\Omega_{\mathrm{d}}>_{\text {low }}\right.$ are PDMS chains with low crosslink density (see text).

Figure 8. Results of deconvolution of MQ growth curves for all samples studied here using FTIKREG regularization and fitting with FitYK as a function of synthesis variable. $\left\langle\Omega_{\mathrm{d}}\right\rangle_{\text {high }}$ is the PDMS chains with high crosslink density, while $<\Omega_{\mathrm{d}}>_{\text {low }}$ are PDMS chains with low crosslink density (see text).

Figure 9. (A) MQ growth curves for swollen and pristine LK3626 sample with results of two component fit to equation $\{4\}$. (B) Distributions of residual dipolar couplings from FTIKREG regularization and fitting with FitYK. 


\section{FIGURES}

Figure 1: Illustration of the network structure and the starting materials used to formulate the networks studied here. Foams were prepared and characterized with varying amounts of PDMS with three MW distributions, with varying amounts of PMHS, and with PMHS with varying numbers of functional crosslinking sites, $\mathrm{n}$.

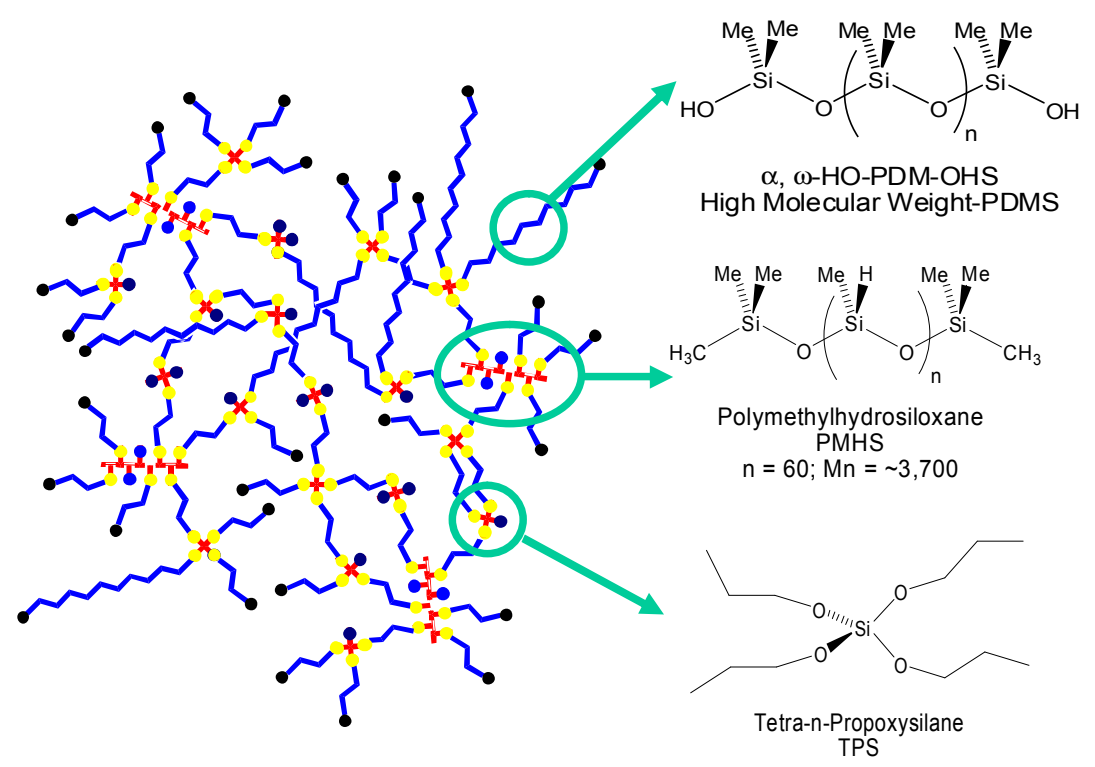


Figure 2. Gel-Permeation Chromatography traces for the three starting PDMS polymers used to generate the networks studied here. (A) High molecular weight between crosslinks component; (B) medium molecular weight between crosslinks component; (C) low molecular weight between crosslinks component.

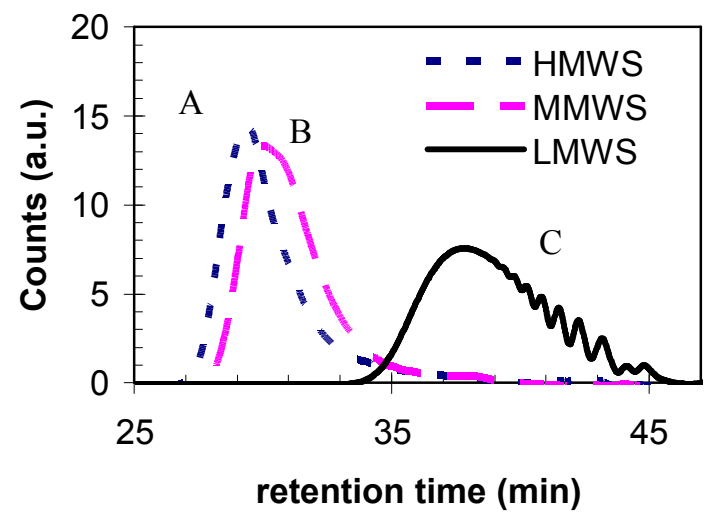


Figure 3: (A) ${ }^{1} \mathrm{H}$ MQ Pulse Sequence used in this study. The number of pulse trains, $\mathrm{n}_{\mathrm{c}}$, was incremented to generate growth curves. Phasing of the detection pulse was alternated to generate the reference curve. The raw growth curve and the reference data set were combined as discussed in the experimental section to generate growth curves that are dependent on crosslink density, as shown in (B).

A

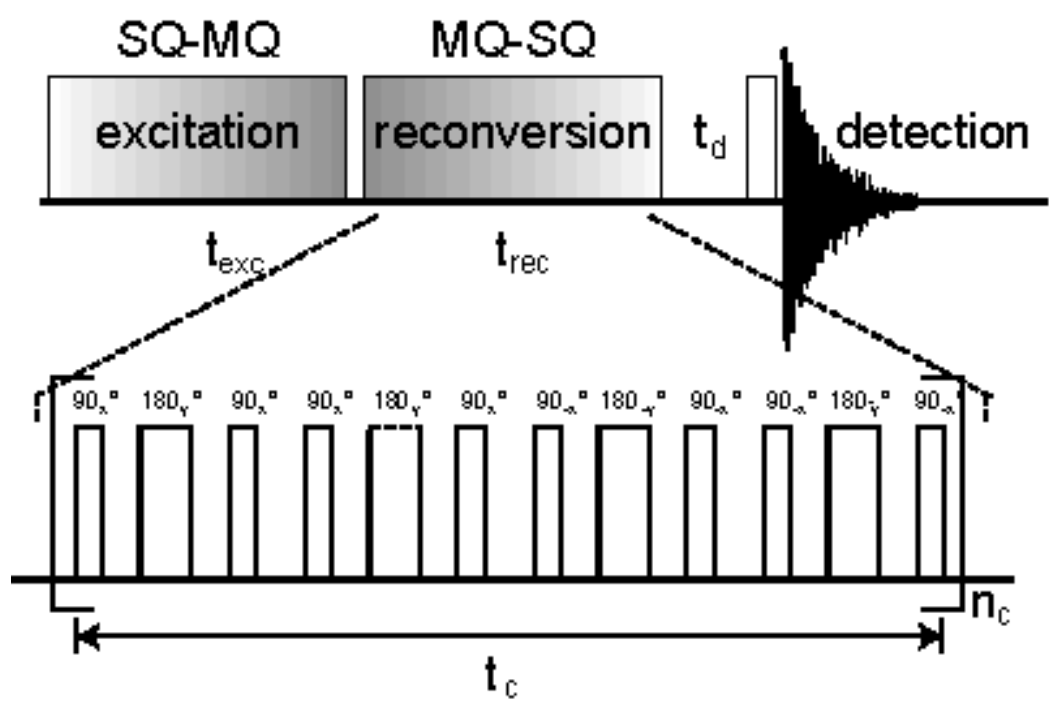

$\mathrm{B}$

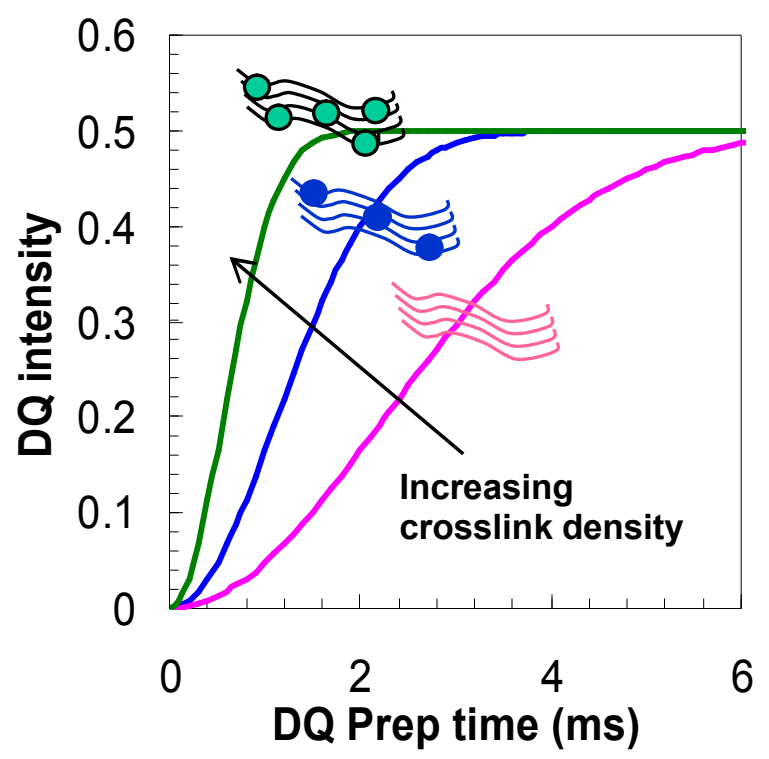


Figure 4: A) MQ growth curve for pristine LK3626 (diamonds) with bi-exponential fit (dashed line). Also shown are the normalized growth curves for the two domains that contribute to the bi-exponential fit. (B) Distribution of residual dipolar couplings $<\Omega_{\mathrm{d}}>$ obtained from FTIKREG regularization of the buildup curve in (A). Solid lines are the fits of Gaussian line shapes to the two overlapping distributions. Dashed line is the overall fit obtained by summing the two Gaussian distributions.
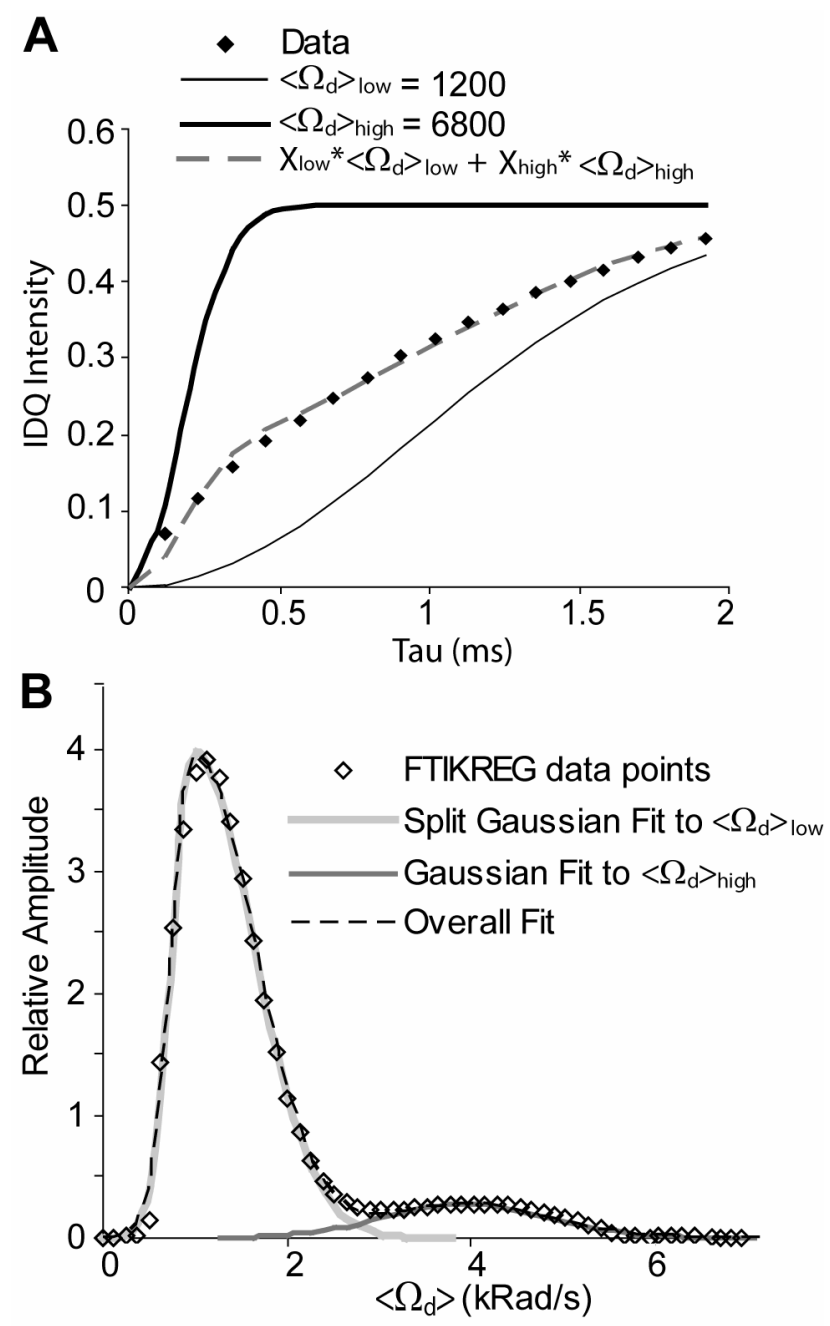
Figure 5: Loads required to reach given compressive strain for the materials studied here: (A) stressstrain curves for three samples in the HMW content study (solid: 83.9 wt.\%; dashed: 86.5 wt.\%; dotted: 89.2 wt.\% ) with compressions of $22 \%, 47 \%$, and $50 \%$ shown as diamonds, squares, and triangles, respectively.

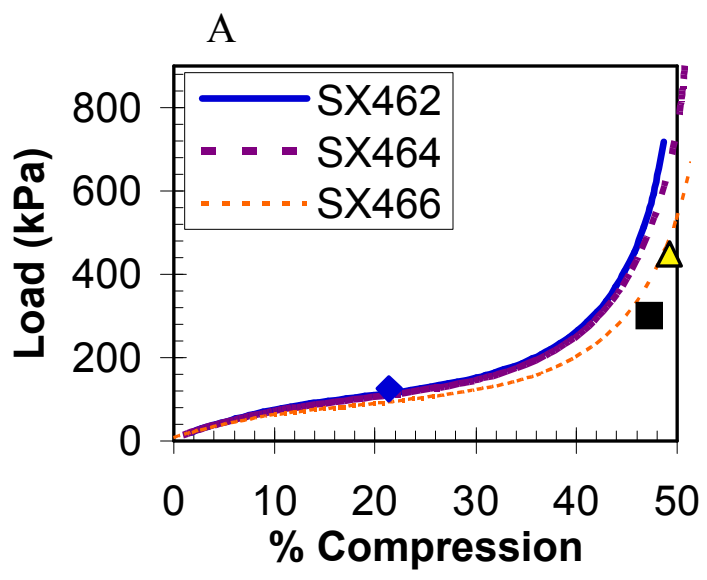


Figure 6: Results of load retention testing (A-C), spin-echo (D-F) and swelling (G-I) analysis of the samples studied here. (A) load at the indicated compressive strains for samples synthesized with varying amounts of high molecular weight vs low molecular weight chains; (B) load at indicated compressive strains for samples synthesized with varying amounts of the highly functional crosslinking site PMHS; and (C) load at the indicated compressive strains for samples synthesized with the MW of the PMHS crosslinking chains increased. (D-F) results of analysis of spin-echo decay curves for same samples. (GI) $\%$ increase in mass after swelling in toluene for same samples in (A-C)

A

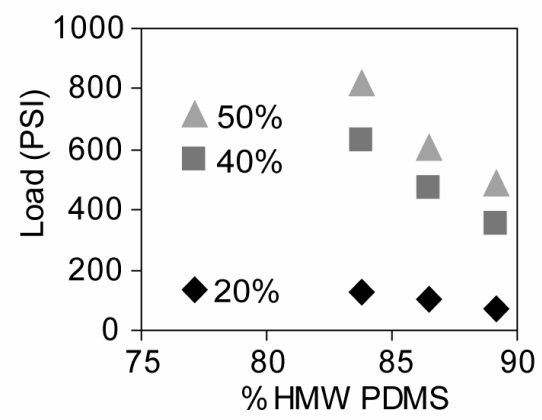

D

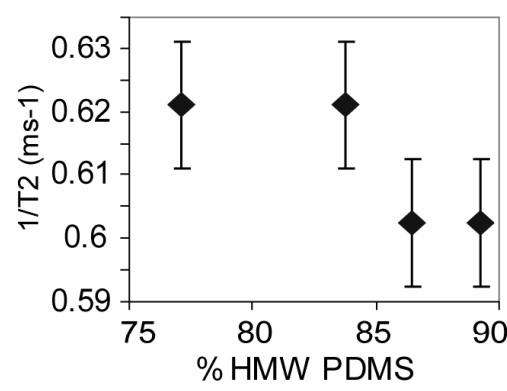

G

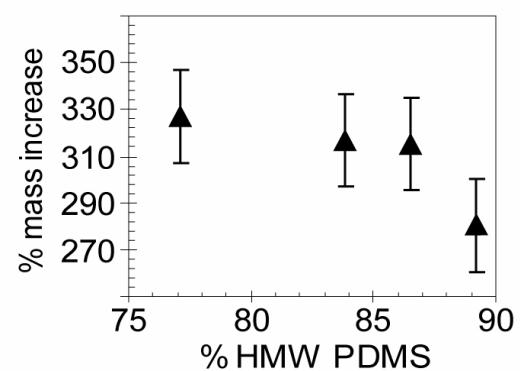

B

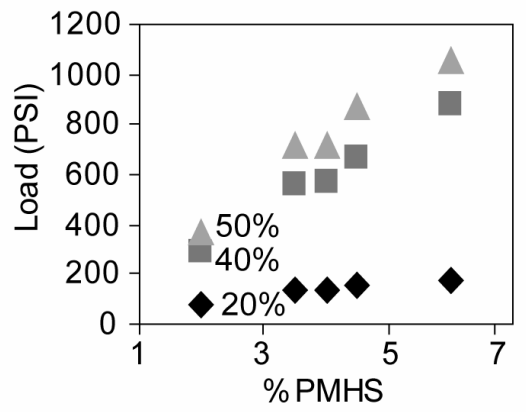

E

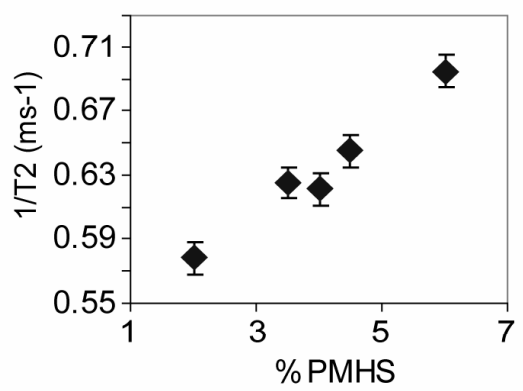

\section{H}

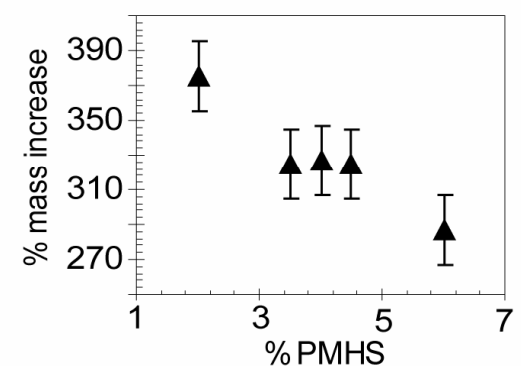

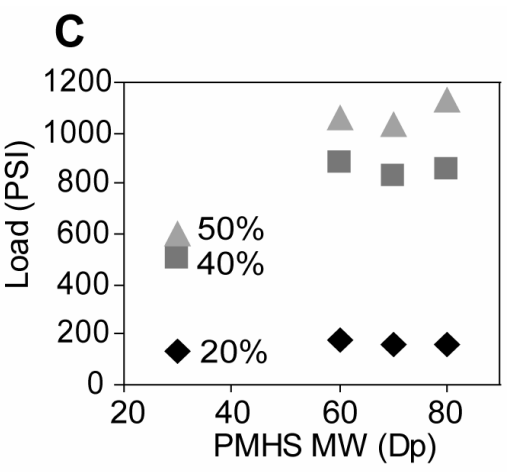

F
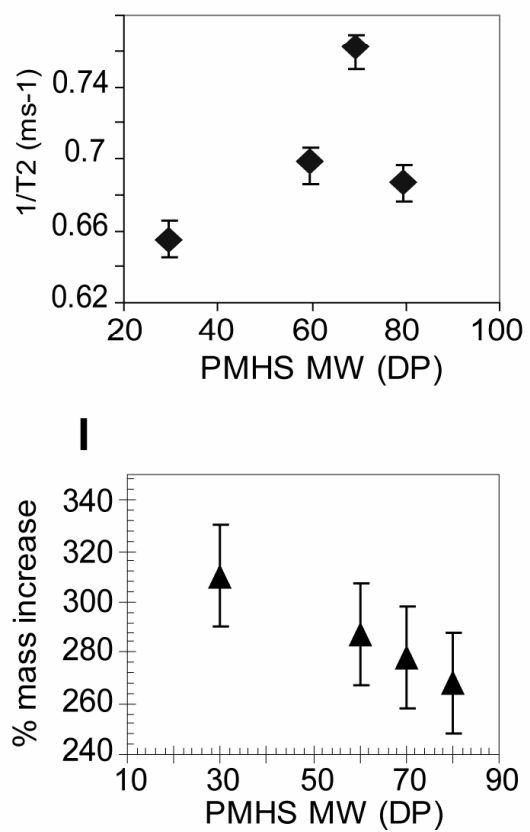
Figure 7. Results of deconvolution of MQ growth curves for all samples studied here to equation $\{4\}$ with two sites plotted as a function of synthesis variable. $\left.<\Omega_{\mathrm{d}}\right\rangle_{\text {high }}$ is the PDMS chains with high crosslink density, while $\left\langle\Omega_{\mathrm{d}}\right\rangle_{\text {low }}$ are PDMS chains with low crosslink density (see text).
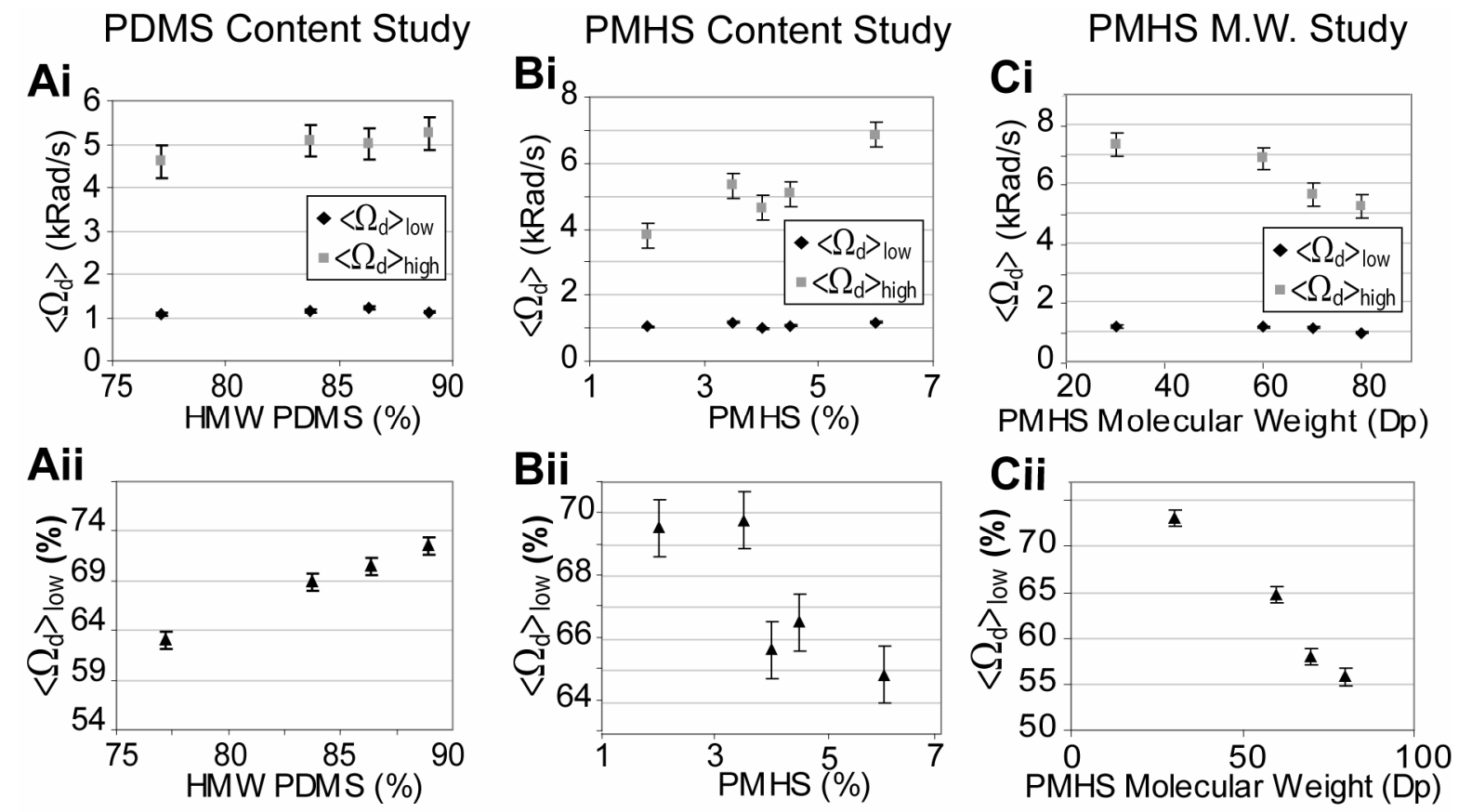
Figure 8. Results of deconvolution of MQ growth curves for all samples studied here using FTIKREG regularization and fitting with FitYK as a function of synthesis variable. $\left\langle\Omega_{\mathrm{d}}\right\rangle_{\text {high }}$ is the PDMS chains with high crosslink density, while $<\Omega_{\mathrm{d}}>_{\text {low }}$ are PDMS chains with low crosslink density (see text).
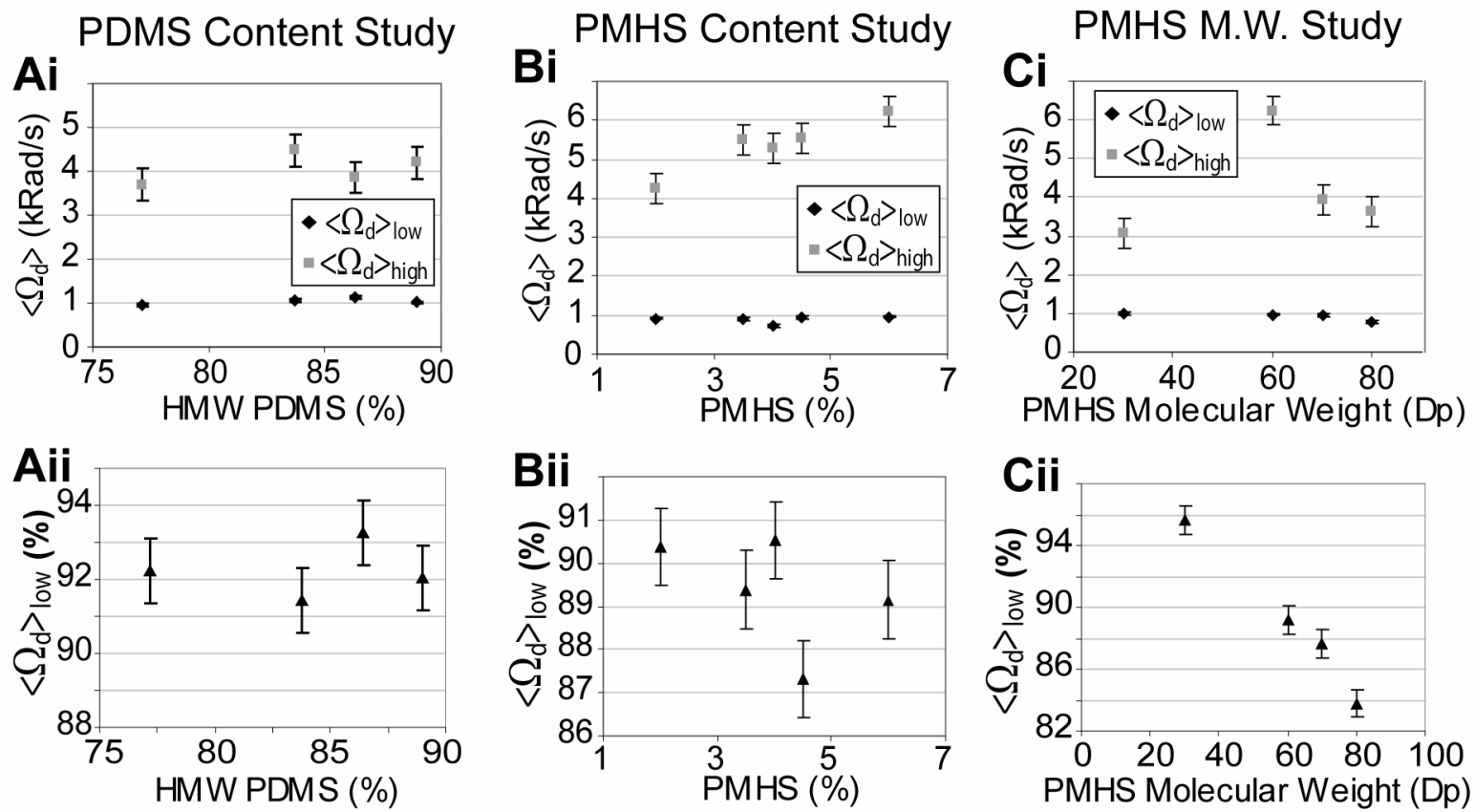
Figure 9: (A) MQ growth curves for swollen and pristine LK3626 sample with results of two component fit to equation $\{4\}$. (B) Distributions of residual dipolar couplings from FTIKREG regularization and fitting with FitYK.
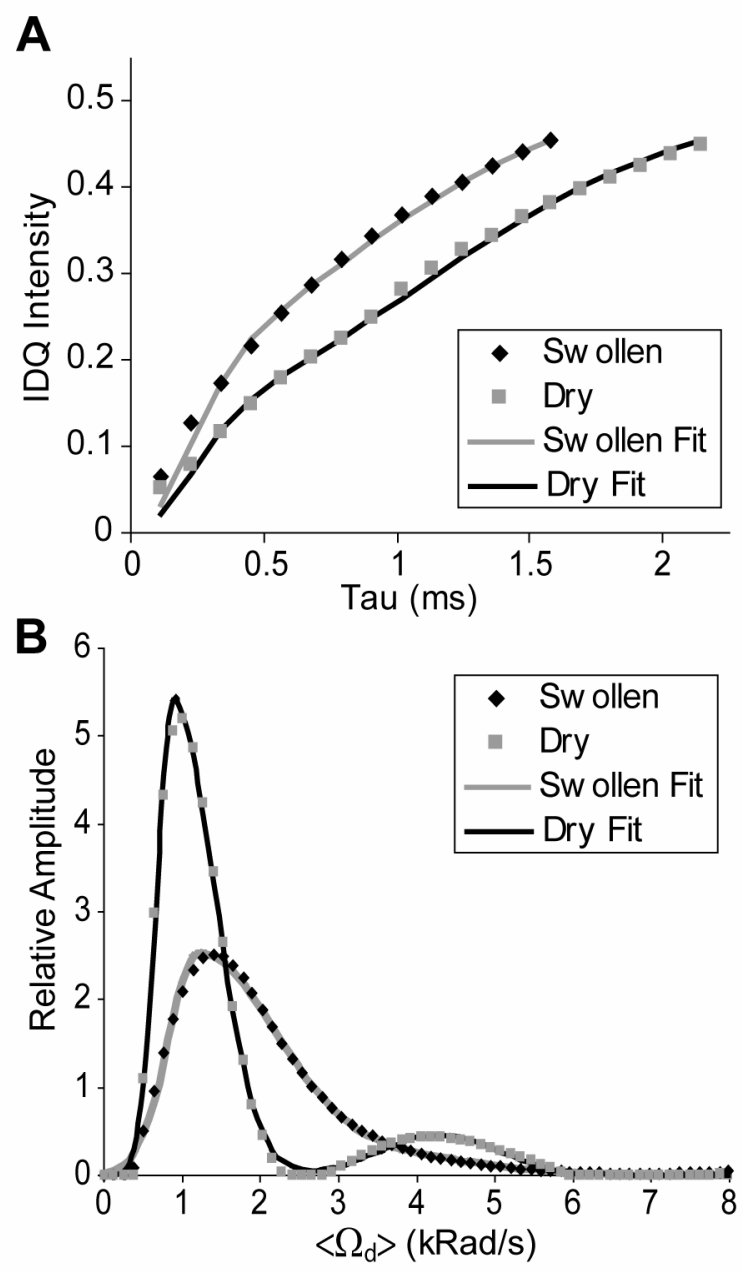